\title{
Passenger Exposure to Magnetic Fields due to the Batteries of an Electric Vehicle
}

\author{
P. Moreno-Torres Concha, P. Velez, M. Lafoz and J. R. Arribas
}

\begin{abstract}
In electric vehicles, passengers sit very close to an electric system of significant power. The high currents achieved in these vehicles mean that the passengers could be exposed to significant magnetic fields. One of the electric devices present in the power train are the batteries. In this paper, a methodology to evaluate the magnetic field created by these batteries is presented. First, the magnetic field generated by a single battery is analyzed using finite elements simulations. Results are compared to laboratory measurements, taken from a real battery, in order to validate the model. After this, the magnetic field created by a complete battery pack is estimated and results are discussed.
\end{abstract}

Index Terms - Electric vehicles, batteries, modeling, magnetic field measurement, occupational safety.

\section{INTRODUCTION}

THE effects of electromagnetic fields (EMFs) on the human health have been investigated for decades [1-3]. Several studies have tried to prove the relationship between long-term exposure to electromagnetic fields and different health pathologies, without totally succeeding. The consequences of a long-term exposure to low frequency EMFs are very difficult to evaluate due to the uncertainty inherent in the scientific data. On the other hand, there is enough scientific basis to state that exposure to low-frequency electric fields may cause well-defined biological responses and Physiological effects[4].

In this context, some countries adopted a regulatory framework based on prevention criteria or guidelines developed by different institutions. These recommended exposure limits to EMFs are high when compared to most usual field values existing in domestic and work environments.

With the recent developments in hybrid and electric vehicles (EVs), the evaluation of the electromagnetic environment in the interior of these vehicles becomes necessary [5-8]. EVs have an electric system of significant power, consisting of batteries, power converters and electric motors (besides all the connecting wires).
In most current EVs designs, some of the components are located very close to the passengers (for instance, it is usual to place the battery pack as far as possible from the bodywork to minimize the risk of battery damage and its consequences in case of crash; this implies positioning them just under or behind the passenger seats [9]). Consequently, there might be hundreds of amperes circulating a few centimeters away from the occupants of the EV during accelerations or deep regenerative braking.

EMFs in hybrid and EVs have been recently analyzed from the electromagnetic compatibility point of view [10-13]. The study in [11] focuses on the batteries and the DC/DC converter, akin to the scope of this paper. Similarly, there are a few recent studies regarding EMFs and health issues in hybrid and EVs [5-8, 14-17]. Most of these works are based on real in-vehicle measurements (some of them under dynamic driving conditions), while others use numeric simulation. For instance, [7] and [8] present results for 11 conventional and electric vehicles and 10 conventional and hybrid vehicles, respectively. On the other hand, finite element simulations are used in [15-17] to analyze the MF threat and to assess the effectiveness of certain mitigation measures (power devices positioning and magnetic shielding).

Traction batteries are potentially one of the main MF sources within an EV. Although they work with DC current in steady state, current transients due to dynamic driving and current ripple caused by the power converter commutations will undoubtedly generate time-varying MFs around the batteries. Moreover, batteries are usually very close to the passengers, and there are many of them within each EV. Because of all the reasons stated above, batteries might be equally or even more significant to total in-vehicle exposure than other field sources.

The study presented in this paper was conceived to analyze and quantify the MF generated by the traction batteries of an $\mathrm{EV}$, in an attempt to investigate the possible MF exposure due to them and to help understand some properties of this field.

\section{EXPOSURE LIMITS TO ELECTROMAGNETIC FIELDS}

The most extended criteria for recommended exposure limit to EMFs were first proposed by the International Commission on Non-ionizing Radiation Protection (ICNIRP) [3]. Concerning static and low frequency MFs (1 Hz to $100 \mathrm{kHz}$ ), 
special revised guidelines were published in 2009 and 2010 [4, 18], in an attempt to include the results of the main scientific publications up to those years.

In summary, ICNIRP's reference levels for Static Magnetic Fields is $400 \mathrm{mT}$ for general public (EVs passengers included) [18]. Concerning time-variant fields, reference levels to EMFs for general public are given in Table I [4]. As stated in [7], it is considered that if the exposure environment complies with the field reference levels then it can be assumed that the exposure limits, which are given in terms of in-body quantities, will not be breached. It is also important to clarify that these guidelines are not legally mandatory, and that become legally binding only if a country incorporates them into its own legislation [19].

\section{Finite ElEment Simulation Model}

In a first step, a 3D Finite Element Model (FEM) was developed to calculate the MF induced by an EV battery module. Once validated, this FEM would allow for the estimation of the magnetic field generated by any battery pack (of a given battery model), regardless the number of modules and their physical distribution.

A model as generic as possible is always desirable, so that it may be used for many different battery models. However, a specific FEM had to be built in this case for the sake of precision, since the battery geometry plays an important role concerning MFs. The only way to accurately model where the current flows through is to consider a particular battery geometry and its current paths.

The modeled battery is the NHE 10-100 module from SAFT, with a nominal voltage of $12 \mathrm{~V}$, a rated capacity of 100 $\mathrm{Ah}$ at $\mathrm{C} / 3$, and a maximum output current of $300 \mathrm{~A}$. Applications for this module include all-electric vehicles.

\section{A. Model Description.}

As the circulating currents are the only producers of MF inside the battery, the elements considered were the following:

1) The cells inside the battery (10 in this case), each one consisting in a blue rectangular parallelepiped with two upper terminals, colored in red and black in Fig. 1.

2) Two vertical cylinders that lengthen the cell terminals along each cell, also in red and black in Fig. 1. The purpose of these cylinders, which are not present in the real battery, is to emulate how the current distributes within a cell, as explained later in this section.

TABLE I

REFERENCE LEVELS FOR GENERAL PUBLIC EXPOSURE TO TIME-VARYING MAGNETIC FIELDS

\begin{tabular}{ccc}
\hline \hline Frequency $(\mathrm{Hz})$ & $\begin{array}{c}\text { Magnetic field } \mathrm{H} \\
(\text { Am-1) }\end{array}$ & $\begin{array}{c}\text { Magnetic flux } \\
\text { density B (T) }\end{array}$ \\
\hline $1-8 \mathrm{~Hz}$ & $3.2 \cdot 10^{4} / \mathrm{f}^{2}$ & $4 \cdot 10^{-2} / \mathrm{f}^{2}$ \\
$8 \mathrm{~Hz}-25 \mathrm{~Hz}$ & $4 \cdot 10^{3} / \mathrm{f}$ & $5 \cdot 10^{-3} / \mathrm{f}$ \\
$25 \mathrm{~Hz}-400 \mathrm{~Hz}$ & $1.6 \cdot 10^{2}$ & $2 \cdot 10^{-4}$ \\
$400 \mathrm{~Hz}-3 \mathrm{kHz}$ & $6.4 \cdot 10^{4} / \mathrm{f}$ & $8 \cdot 10^{-2} / \mathrm{f}$ \\
$3 \mathrm{kHz}-10 \mathrm{MHz}$ & 21 & $2.7 \cdot 10^{-5}$ \\
\hline \hline
\end{tabular}

Notes:

- $\quad \mathrm{H}$ and $\mathrm{B}$ in unperturbed rms values.

- In addition, reference levels relating to tissue heating effects need to be considered for frequencies above $100 \mathrm{kHz}$.

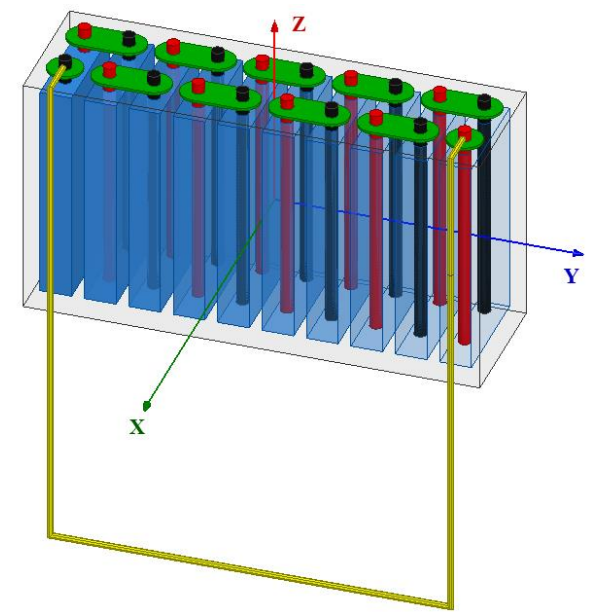

Fig. 1. 3D finite element model for a NiMH battery. For the sake of clarity, the transparency of the cells in Fig. 1 changes gradually from cell to cell.

3) The metal splints joining the positive terminal of each cell with the negative terminal of the next cell (in green).

4) An external yellow wire $(25 \mathrm{~mm} 2)$ short-circuiting the battery. This wire is modeled so that its shape is similar to the real wires used during the laboratory tests.

5) A box representing the external dimensions of the battery just for the sake of illustration.

In order to simplify the calculations, the following consideration was made concerning the geometry and materials of the $\mathrm{FEM}^{1}$. In the NiMH battery, the current inside each cell is considered to flow as depicted in Fig. 2 (discharge mode): The current enters the cell through the negative terminal and goes to the negative electrodes, composed of hydrogen ions stored in a metal hydride structure (colored in black in Fig. 2). From there, the current flows through the electrolyte to reach the positive electrode, which are nickel hydroxide plates (depicted in red in Fig. 2).

Modelling all these metallic plates (several plates per cell, ten cells per battery) is computationally prohibitive in a 3D finite element model, and breaks the purpose of the simulation tool. In order to simplify the FEM, the current flow in the yaxis direction is neglected based on the following considerations:

1) The distance $\Upsilon$ that the current travels in the y-axis direction (i.e. the separation between electrodes) is considerable shorter than the distance $\chi$ travelled in the $\mathrm{x}$-axis direction (i.e. the length of the electrodes).

2) The distance $Y$ is negligible when compared to the distance from the battery to the passengers.

3) Within the same cell, current flows in both the y-axis

${ }^{1}$ It is important to state here that this paper does not seek to describe the real currents that take place deep inside a battery. As it is well known, the electrolyte is an ionic conductor that provides the medium for the transfer of charge, and it must have good ionic conductivity but not be electronically conductive, as this would cause internal short-circuiting. Inside a battery, between the anode and cathode, the amperes of current appear as a flow of both positive and negative atoms, whilst for the external circuit this current consists in a flow of electrons [20].

This paper focuses on the effects of those currents in terms of MF, in points far enough from the battery so that it is not necessary to consider the real nature of the current phenomena. Therefore, a conventional electric current convention (flow of positives charges from + to -) is used in this work. 
positive and negative direction, thus cancelling out the MFs generated by each of them. Contrarily, current flows either in the $\mathrm{x}$-axis positive or negative direction in a given cell.

Therefore, the electrodes plates in the real battery may be substituted by a solid conductor (i.e. an "emulated electrolyte", colored in blue in Fig. 1), as shown in Fig. 3.

In order to make the current flow through different heights within the cell, the cell terminals need to be lengthened in the negative $z$-axis direction. Otherwise, the current would flow directly from one terminal to the other, without travelling through most of the cell. Besides, the ratio between the electrical conductivity of the terminal material $\sigma_{\mathrm{T}}[\mathrm{S} / \mathrm{m}]$ and the emulated electrolyte material $\sigma_{E}$ needs to be chosen carefully so as to achieve a proper current distribution within the cell, as shown in Fig. 4 (b). In this particular case, copper $\left(\sigma_{\mathrm{T}}=58 \cdot 10^{6}\right)$ was used for the terminals, the metal splints and the external wire, while a generic fluid with $\sigma_{\mathrm{E}}=\sigma_{\mathrm{T}} / 10^{6}=58$ was used for the emulated electrolyte. This value is actually close to the real NiMH electrolyte conductivity, typically a solution of $\mathrm{KOH}(22 \%, \mathrm{~d}=1.2 \mathrm{~g} / \mathrm{cm} 3)$ containing some $\mathrm{LiOH}(8-20$ $\mathrm{g} / \mathrm{l})$, which is in the range of $10-50 \mathrm{~S} / \mathrm{m}[20]$.

The FEM has one single current loop, comprising the external wire as well as all the cells and their terminals. For all the simulations presented hereafter, the circulating current is in the form of

$$
i(t)=I_{D C}+I_{A C} \cdot \operatorname{triangle}\left(t, T_{S W}\right)
$$

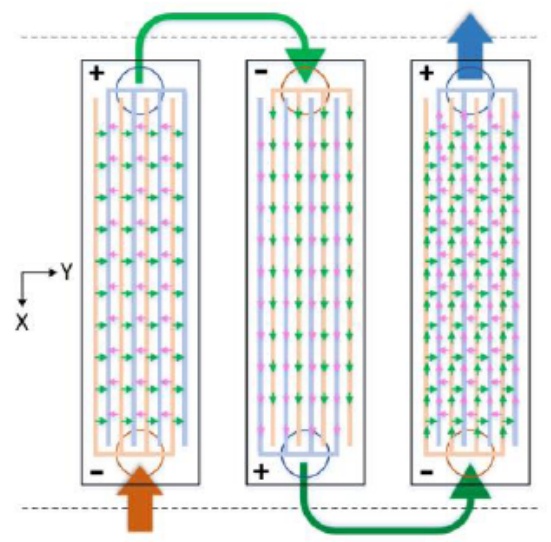

Fig. 2. Current flow (discharge mode) inside three cells of a NiMH battery, seen from above. The cell on the left shows current in the y-axis direction, the cell in the middle shows current in the $\mathrm{x}$-axis direction, and the cell in the right shows current in both directions.

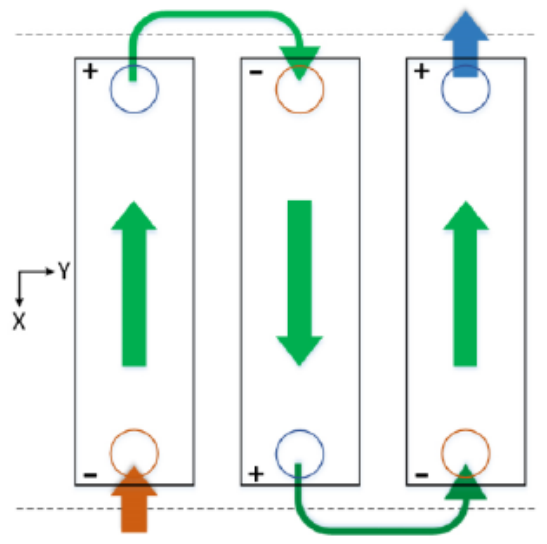

Fig. 3. Simplification of the current flow (discharge mode) inside three cells of the battery, seen from above. Current in the $\mathrm{y}$-axis direction is neglected.

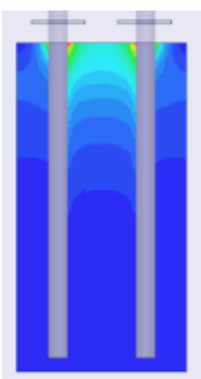

(a)

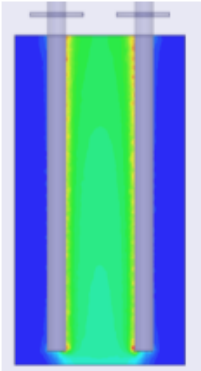

(b)
Fig. 4. Current density across one battery cell: relative comparison between (a) an improper $\sigma_{\mathrm{T}} / \sigma_{\mathrm{E}}$ ratio $\left(10^{2}\right)$, and (b) an adequate $\sigma_{\mathrm{T}} / \sigma_{\mathrm{E}}$ ratio $\left(10^{6}\right)$.

where triangle $\left(t, T_{S W}\right)$ is a triangle wave of amplitude \pm 1 A and period

$T_{S W}=1 / f_{S W}$

$f_{S w}$ being the switching frequency of the power electronics converter drawing/injecting current from/to the batteries. This current waveform, along with the real battery current measured in the laboratory tests, is depicted in Fig. 5.

\section{B. Simulation Results.}

Several transient simulations were run with different values of the parameters IDC, $I_{A C}$ and $f_{S W}$ (see Table II). All the simulations had the geometry, materials and mesh in common, the only difference being the current.

Due to the high number of finite elements needed in a 3D model, special volumetric regions were defined around each axis with a refined mesh to decrease the number of elements without affecting accuracy. In this sense, the MF was calculated in three axes coming out from the center of three sides of the battery: X-, Y- and Z+ (as defined in Fig. 1).

Simulation results for all the above cases are shown in the following section, along with measurement results.

\section{LABORATORY MEASUREMENTS}

\section{A. Measurement Procedure.}

Laboratory measurements were taken on a single $\mathrm{NiMH}$ battery module. Both DC and AC (RMS) MFs were measured by means of two MF meters (F.W. Bell 5170 for DC and Combinova MFM10 for AC).

The laboratory set up, described in detail in [21], consisted in four battery modules connected in series to a full-bridge DC/DC power converter (conventional three-phase IGBT bridge with anti-parallel diodes [22, 23], although more advanced topologies such as three-level converters could be used instead within the same methodology). The DC/DC converter worked as a bidirectional multiphase (interleaved topology) buck-boost converter [22]. The DC/DC control

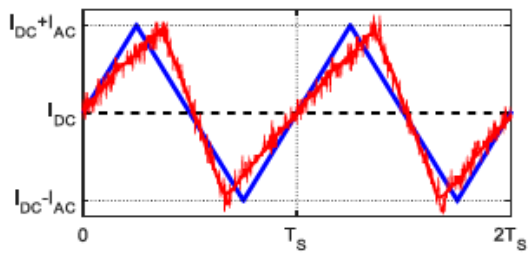

Fig. 5. Parameterized current waveform used in the simulations and real current as measured in the laboratory. 
TABLE II

SIMULATED CASES

\begin{tabular}{ccc}
\hline \hline $\begin{array}{c}\text { Frequency } \mathrm{f}_{\mathrm{SW}} \\
(\mathrm{kHz})\end{array}$ & $\begin{array}{c}\text { Current ripple } \mathrm{I}_{\mathrm{AC}} \\
(\mathrm{A})\end{array}$ & Current $\mathrm{I}_{\mathrm{DC}}(\mathrm{A})$ \\
\hline 1 & 18.68 & \pm 50 and \pm 100 \\
\hline 2 & 9.41 & \pm 50 and \pm 100 \\
\hline 5 & 4.10 & \pm 50 and \pm 100 \\
\hline
\end{tabular}

strategy was responsible for imposing the battery current $\mathrm{I}_{\mathrm{BAT}}$ regardless the battery and DC-link voltages, while protecting the battery from overcurrent, overcharge and overdischarge. The modulation strategy was PWM with interleaving.

One of the four battery modules was physically distanced from the rest in order to isolate it from the MF point of view. Unlike in the FEM, the external wire could not be completely removed in this case, although the pair of wires connecting this module to the rest were tied up together so as to minimize the MF created by them, as shown in Fig. 6 .

Measurements were taken considering different distances and different working points of the batteries. Three axes were taken into account: $\mathrm{X}-, \mathrm{Y}-$ and $\mathrm{Z}+$.

As in [15], a small offset was subtracted to the measured values in order to correct the background residual magnetic field. Similarly, a position-dependent calibration factor was applied to the measurements in order to compensate both the spatial averaging due to the size of the sensors and the reduced coupling that exists when measuring a local source.

\section{B. Measurement Results. Comparison with Simulation Results.}

Fig. 7 shows both the simulated and the measured values of both the AC and DC magnetic field for axes X-, Y- and Z+, as a function of the switching frequency (AC measurements) and the current level (DC measurements). Note that no distinction is made concerning the sign of the current, because the differences found between charging and discharging were not statistically significant. In this sense, it is concluded that the MF created by the battery is the same during charge than during discharge.

The agreement between simulations and measurements is

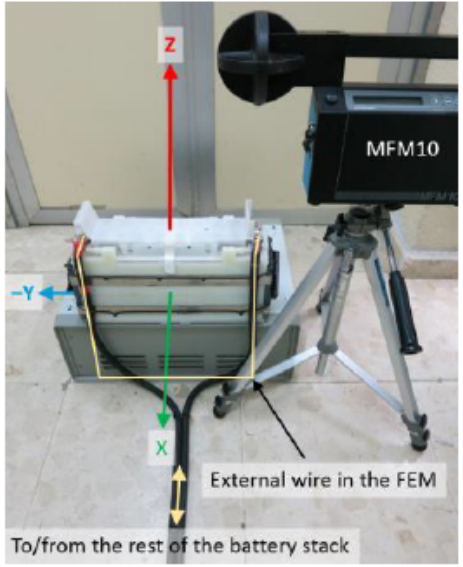

Fig. 6. Test bench for the measurements of the MF generated by one battery module.

sufficiently good, the largest absolute deviation being less than $1.2 \mu \mathrm{T}$ and $19 \mu \mathrm{T}$ for AC and DC, respectively. Relative error is not that important in this case because the aim of the study is to compare these results to the exposure limits recommended by the ICNIRP [4], which is done in next section. Therefore, the proposed simulation methodology is considered valid to make estimations of the magnetic field environment generated by a given battery pack under varied working conditions.

\section{EVALUATION OF THE RESUltS}

\section{A. Single Battery Module Analysis.}

In this subsection, the MF created by the battery module is compared to ICNIRP's reference levels for different currents and switching frequencies. In order to establish a comparison, it is considered that the battery is placed inside the vehicle so that the closest passenger will be at $20 \mathrm{~cm}$ in the $\mathrm{Z}+$ direction (worst-case scenario). This short distance between a battery and a passenger is only possible if the battery is just below the seat in which the passenger is sitting. Therefore, $\mathrm{Z}$ will be the only axis considered from now on.

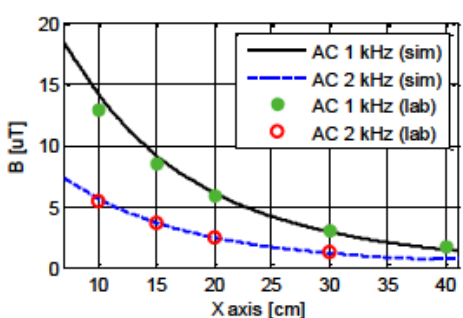

(a)

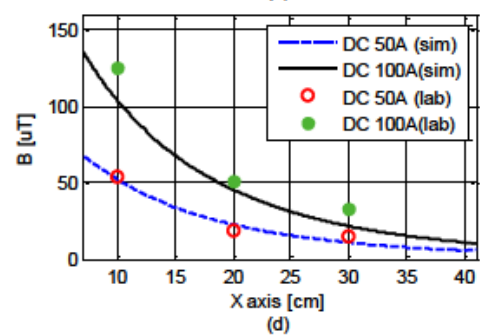

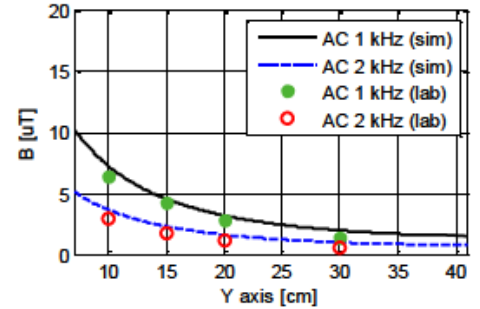

(b)

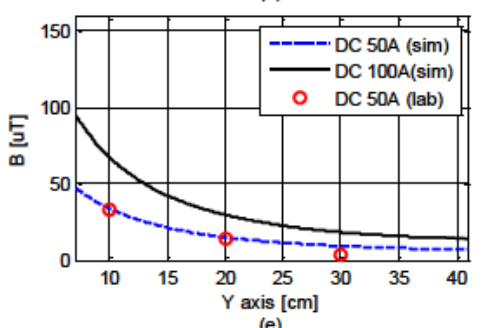

(e)

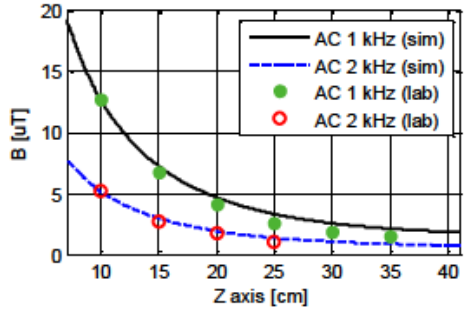

(c)

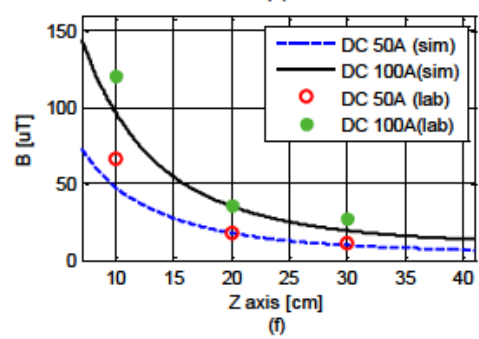

Fig. 7. $\mathrm{AC}$ and $\mathrm{DC}$ magnetic induction (RMS values): comparison between simulation results (lines) and laboratory measurements (points) for both $1 \mathrm{kHz}$ and 2 $\mathrm{kHz}$ ripple in (a) $\mathrm{X}$ axis; (b) $\mathrm{Y}$ axis; and (c) $\mathrm{Z}$ axis; and for both $50 \mathrm{~A}$ and $100 \mathrm{~A}$ in (d) $\mathrm{X}$ axis; (e) $\mathrm{Y}$ axis; and (f) $\mathrm{Z}$ axis. 


\section{1) Magnetic Field Analytical Approximation.}

Despite its relative simplicity, the 3D FEM could be too time consuming to be considered a good estimation tool. Therefore, an analytical model is desirable, at least when linearity exits between the MF magnitude and the current level (DC case) or the switching frequency (AC case).

A curve-fitting tool may be used to derive analytical expressions in the form of reciprocal power equations such as

$B(z)=K_{1} / z^{K_{2}}$ (with $\mathrm{B}$ in $\mu \mathrm{T}$ and $z$ in $\mathrm{m}$ )

for the simulation results depicted in Fig. 7 (c) and (f), resulting:

$\left|\vec{B}_{D C, Z}\right|_{50 \mathrm{~A}}=1.816 / z^{1.416}$

$\left|\vec{B}_{D C, Z}\right|_{100 \mathrm{~A}}=3.599 / z^{1.420}$

$\left|\vec{B}_{A C, Z}\right|_{1 k H z}=0.4798 / z^{1.417}$

$\left|\vec{B}_{A C, Z}\right|_{2 k H z}=0.1963 / z^{1.416}$

For reasons explained later in the paper, an additional simulation was performed at $5 \mathrm{kHz}$, obtaining (4e). Fig. 8 shows the fitness of the analytical approximation for the three switching frequencies taken into account.

$\left|\vec{B}_{A C, Z}\right|_{5 \mathrm{kHz}}=0.1217 / \mathrm{z}^{1.420}$

All five equations have a similar exponent $\mathrm{K}_{2}$, which means that the MF attenuates with the distance to the battery at the same rate in all cases. Regarding DC MF, coefficient $\mathrm{K}_{1}$ shows that there is linearity between the MF magnitude and the current level IDC (as expected). Consequently, (4a) and (4b) may be further generalized as follows:

$$
\left|\vec{B}_{D C, Z}\right|=0.03615 \cdot I_{D C} /_{Z^{1.418}}
$$

However, in the case of AC there is no linearity between the MF magnitude and the switching frequency $f_{S W}$. This fact is due to the non-linearity between $\mathrm{f}_{\mathrm{SW}}$ and the current ripple $\mathrm{I}_{\mathrm{AC}}$, which is illustrated in Fig. 9. Therefore, (4c), (4d) and (4e) can also be generalized just by using an analytical approximation of that non-linear relationship (dashed line in Fig. 9):

$I_{A C}\left(f_{S W}\right)=K_{3} \cdot x^{K_{4}}=\frac{18.61}{f_{S W}{ }^{0.9517}}$

which yields (under the assumption of lineal dependence of the magnetic field with the current ripple, i.e. quasistatic approximation of Maxwell's equations):

$\left|\vec{B}_{A C, Z}\right|=K_{5} \cdot I_{A C} /_{Z^{1.418}}=\frac{0.4671}{z^{1.418} \cdot f_{S W^{0.9517}}}$

where $\mathrm{B}$ is in $\mu \mathrm{T}, \mathrm{z}$ is in $\mathrm{m}, \mathrm{fsw}_{\mathrm{Sw}}$ is in $\mathrm{kHz}$ and $\mathrm{K}_{5}$ is 0.0251 .

2) Magnetic Field Generated by a Single EV Battery.

In an instant of strong acceleration of the vehicle, battery current can reach levels as high as $3 \mathrm{C}$ (300 A for this

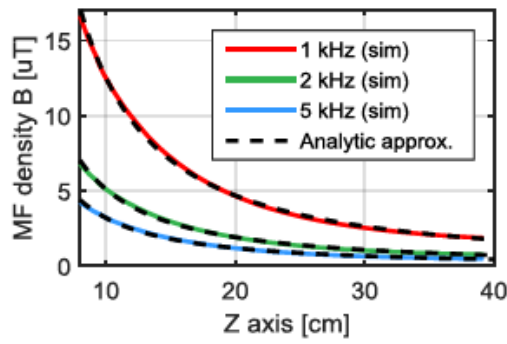

Fig. 8. Magnetic flux density (simulations and analytical approximations) for three different switching frequencies. particular battery). In such case, a single module would create a temporary DC MF of up to $105.9 \mu \mathrm{T}$, according to (4f). This value is far below ICNIRP's reference level for static MF exposure $(400 \mathrm{mT}$ for general public and down to $500 \mu \mathrm{T}$ for especially sensitive public, such as individuals with medical implants).

However, this DC MF must not be considered as a timeinvariant MF due to its transitory nature. In an EV application, current peaks may have a time constant as short as one second or even less [24], which means that the corresponding MF should actually be analyzed as a multiple-frequency nonsinusoidal exposure $[4,25]$. To do so without adopting unnecessarily conservative assumptions, the method presented in [26] is suggested by ICNIRP. A good example of such an analysis can be found in [17], in which a 50-seconds timevarying, broad-band field exposure (corresponding to a real EV driving profile) is reconstructed via an inverse Fourier transform to accurately take additive effects into account.

As this paper deals only with steady state currents (both simulations and measurements were done in this situation), it is beyond the scope of this work to perform such an analysis. Therefore, only steady-state harmonics are considered in this section as well. The results corresponding to this "transient DC" component are depicted in Fig. 10 (in which simulation results are compared to ICNIRP's reference values) as a sinusoidal MF exposure of frequency up to $2 \mathrm{~Hz}$ just as a remainder of this fact.

As for the AC MF, the higher the switching frequency $\mathrm{f}_{\mathrm{Sw}}$, the lower the MF magnitude, but also the lower ICNIRP's reference level. This means that a detailed analysis is required in this case.

Given that a battery DC-DC converter would rarely have a switching frequency below $1 \mathrm{kHz}$ [27], and considering that ICNIRP's level between $3 \mathrm{kHz}$ and $10 \mathrm{MHz}$ is constant and equal to $27 \mu \mathrm{T}$, three frequency values have been simulated: 1 , 2 and $5 \mathrm{kHz}$, the first two being validated by laboratory measurements, and equation $(4 \mathrm{~g})$ has been derived. This equation can be used to compare the MF generated by one battery $(Z+$ direction, $20 \mathrm{~cm})$ to ICNIRP's reference levels to calculate the worst operating point in terms of switching frequency, as illustrated in Fig 11 (harmonic components neglected). Equation $(4 \mathrm{~g})$ may also be used to calculate the MF generated by a single battery module as a function of the operating point (current and switching frequency), as depicted in Fig. 10.

The results presented in both Fig. 10 and Fig. 11 suggest that choosing a different switching frequency $\mathrm{f}_{\mathrm{Sw}}$ may have an

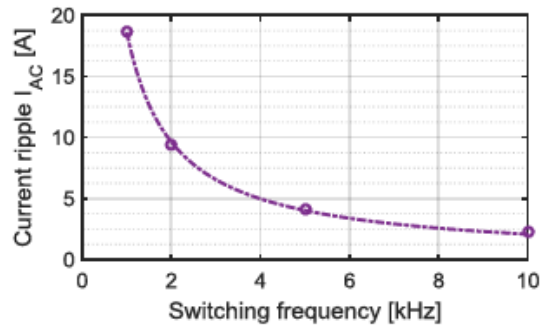

Fig. 9. Current ripple (peak values) vs. switching frequency for the test bench and DC-DC used in this work. 
important impact in the assessment of the MF exposure due to the batteries, the DC-DC converter and the wires connecting them. Given the non-lineal relationship between $\mathrm{f}_{\mathrm{SW}}$ and the $\mathrm{MF}$, and also the non-lineal relationship between the field frequency and ICNIRP's levels, it is clear that some values of fsw will be more advantageous than others. As this value determines the harmonic components of the current frequency spectrum, one must consider the multiple-frequency approach aforementioned to properly optimize switching frequency in terms of MF exposure.

\section{B. Battery Pack Analysis.}

In this subsection, a certain hypothetical EV with a specific battery pack is analyzed from the MF point of view. This pack, shown in Fig. 12, consists of 28 battery modules for a total rated voltage of $336 \mathrm{VDC}$.

Each of these modules is modelled in accordance to the analytic model represented by $(4 \mathrm{f})$ and $(4 \mathrm{~g})$, assuming that they are valid for any off-axis direction (it is actually derived for the $\mathrm{Z}+$ direction, in which the MF reaches highest values), and considering the distance from each of the modules to the closest body parts of the closest passenger. The short distances involved mean that the distribution of the MF is non-uniform. Therefore, the maximum MF value in the position of space occupied by that passenger's body is considered, which results in a safe, albeit very conservative exposure assessment. In this sense, MF is calculated in two different points; both of them are shown in Fig. 12.

In order to calculate the total MF in those two points, superposition principle is applied, so that the contributions of all the modules are algebraically summed:

$|\vec{B}| \leq \sum_{n=1}^{28}\left|\vec{B}_{n}\right|$

Obviously, given the vector nature of the MF, (6) yields an upper bound of the total field (again, worst case scenario).

Under all these assumptions, which are summarized in Table III for convenience, the MF is calculated in the two abovementioned body parts, and for the same four frequencies as previously. Results are shown in Fig. 10 for the most critical body part, which for this particular EV is the seat. It

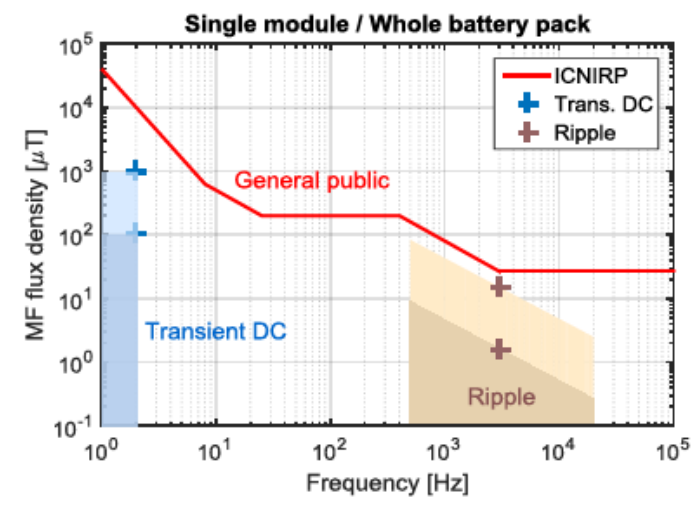

Fig. 10. Comparison between simulation results (transient DC and current ripple ranging from $500 \mathrm{~Hz}$ to $20 \mathrm{kHz}$ ) and ICNIRP's recommended limits for general public (RMS values) for one single module and a whole battery pack, both of them for a distance of $20 \mathrm{~cm}$ between the closest passenger and battery. The colored areas represent the operation zone, which is determined by the current and the switching frequency (darker colors for the single module, lighter colors for the whole pack). can be seen that, despite the conservative assumptions, the MF generated by this specific battery pack is still below ICNIRP's levels.

\section{Considerations Regarding Fast-charge.}

This section has focused hitherto in those situations in which the passengers are sitting inside the EV while driving it, which means that peak battery currents are reached during strong accelerations. Power peaks corresponding to deep regenerative braking [28] are usually lower because of the two following reasons. On one hand, the passive nature of part of the EV motion resistances (rolling and aerodynamic [29]) means that only a fraction of the energy is recoverable. On the other hand, the global energy efficiency of the traction powertrain implies higher battery power during traction mode than during regenerative mode.

Contrarily, fast charging situations yield charge currents of $2 \mathrm{C}$ or even more [30], with higher C-rates available every year due to the impressive developments in battery technology. One could think that no passengers will be inside the EV while charging, but it is also true that the faster the charge, the more likely some of the passengers will remain inside.

In this sense, both strong accelerations and fast charging should be regarded as the two most hazardous situations from the MF point of view.

\section{Other Field Sources within the Vehicle and Other Factors that Influence Exposure.}

So far in this work, only the MF generated by the EV batteries has been considered. However, many other devices within the vehicle act as MF sources, especially power converters and their wires $[6,15]$. In this sense, it is worth noting here that an EV may be considered safe (from the MF exposure point of view and according to ICNIRP's guidelines) only when the total MF is below ICNIRP's levels. Besides, in situations of simultaneous exposure to fields of different frequencies, these exposures might be additive in their effects, which must be taken into account when assessing MF exposure [4].

It is also worth mentioning that there are other factors, apart from the aforementioned field sources, that affect on-board MFs. For example, one of the main sources of MF in

TABLE III

SUMMARY OF HYPOTHESES ADOPTED IN THE BATTERY PACK ANALYSIS

\begin{tabular}{lll}
\hline \hline Hypothesis & Description & Type \\
\hline $\begin{array}{l}\text { Analytical } \\
\text { approximation }\end{array}$ & $\begin{array}{l}\text { Analytical equations derived } \\
\text { from simulations are used in the } \\
\text { analysis. }\end{array}$ & Approximation \\
\hline $\begin{array}{l}\text { Battery/passenger } \\
\text { location }\end{array}$ & $\begin{array}{l}\text { The batteries and the passenger } \\
\text { are placed as close to each other } \\
\text { as possible. }\end{array}$ & $\begin{array}{l}\text { Conservative } \\
\text { (worst case) }\end{array}$ \\
\hline Superposition & $\begin{array}{l}\text { Superposition principle is applied } \\
\text { to a vector magnitude. }\end{array}$ & $\begin{array}{l}\text { Conservative } \\
\text { (worst case) }\end{array}$ \\
\hline Spatial averaging & $\begin{array}{l}\text { Maximum values in the position } \\
\text { of space occupied by the body } \\
\text { are considered. }\end{array}$ & $\begin{array}{l}\text { Very } \\
\text { conservative }\end{array}$ \\
\hline Time averaging & $\begin{array}{l}\text { Peak field values regarded as } \\
\text { instantaneous values (no time } \\
\text { averaging). }\end{array}$ & $\begin{array}{l}\text { Conservative } \\
\text { (worst case) }\end{array}$ \\
\hline $\begin{array}{l}\text { Non sinusoidal } \\
\text { exposure }\end{array}$ & $\begin{array}{l}\text { MF harmonic components are } \\
\text { neglected. }\end{array}$ & Approximation \\
\hline \hline
\end{tabular}




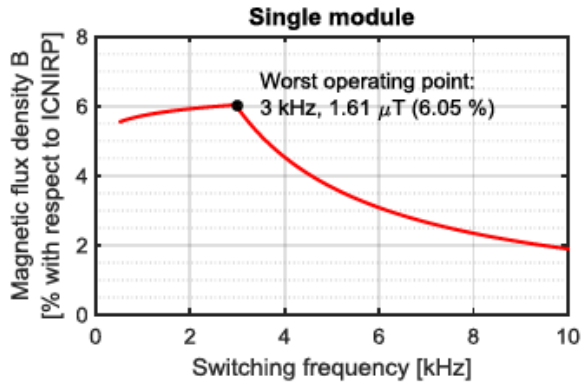

Fig. 11. Magnetic flux density relative to ICNIRP's reference levels as a function of switching frequency.

conventional vehicles is caused by the permanent magnetization of steel belted tires, whose rotating speed determines the fundamental frequency of the corresponding MF (usually up to $15-20 \mathrm{~Hz}$ ) [7, 8]. Additionally, vehicle construction such as bodyshell shape, thickness and materials may have a significant impact on in-vehicle MF levels [16].

\section{E. MF inside Other Vehicles.}

Although the MF values obtained in this study (current harmonics neglected) are below ICNIRP's reference levels, it must be noted that there are many different types of batteries, many possible packs configurations and locations [9], and many different types of EVs, including electric buses, competition cars, or even airplanes [31,32]. Besides, some EVs have hybrid energy storage systems (usually a combination of batteries and supercapacitors) for improved performance [32,33], which means that the MF generated by the latter must also be evaluated. On top of that, it is reasonable to expect that these type of vehicles will grow in power in the following years.

In this sense, it is important to clarify that this work suggests that the MF generated by this particular battery pack, inside this particular EV, should be safe for occupational passengers. However, this result could be very different for other vehicles, or even for this same vehicle when considering the rest of MF sources.

Consequently, the MFs issue in the interior of EVs should be kept under strict surveillance. Until new scientific evidence is found regarding MF exposure, it should be the vehicle

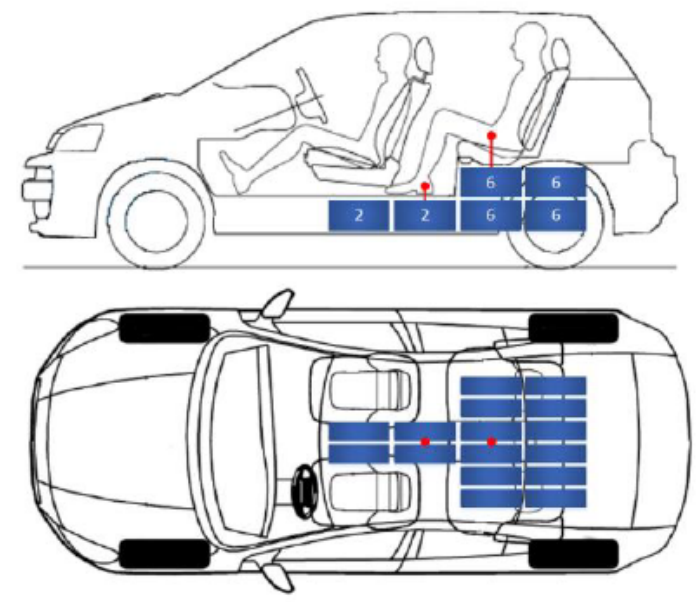

Fig. 12. Battery pack relative location with respect to the passengers. designer's duty to analyze this issue, both by evaluating the MF inside each vehicle model and by taking MF exposure into account when designing. Naturally, in those countries in which there are regulations concerning MF exposure, this duty could become legally mandatory.

In this regard, some design guidelines of electrical nature were presented in [15], based in the As Low As Reasonably Practicable (ALARP) principle. This principle allows the implementation of protection strategies at an acceptable cost, and it is preferably applied during the first stages of the design process of the vehicle. In those cases in which additional measures were needed to further reduce the MF, magnetic shielding systems such as those based on ferromagnetic plates would probably prove useful [34].

\section{CONCLUSIONS}

Passengers inside an electric vehicle could be exposed to magnetic fields of considerable strength when compared to conventional vehicles or to other daily exposures (at home, in the office, in the street, etc.). In this paper, the magnetic field created by the batteries of a particular electric car is evaluated from the human health point of view by means of finite elements simulations, measurements, and a simple analytical approximation, obtaining an upper bound for the estimated magnetic field generated by a given battery pack. These results have been compared to ICNIRP's recommendations concerning exposure limitation to low frequency magnetic fields, finding that the field generated by this particular battery pack should be below ICNIRP's field reference levels, and conclusions concerning the influence of the switching frequency has been drawn. Finally, some discussion regarding other field sources within the vehicle and different vehicles designs has been presented. Due to the wide variety of both available electric vehicles and battery stacks configurations, it is recommended that each vehicle model should be individually assessed regarding magnetic field exposure.

\section{ACKNOWLEDGMENT}

P. Moreno-Torres thanks Lara Rodríguez for her contribution to some of the figures included in this work.

\section{REFERENCES}

[1] National Institute of Environmental Health Sciences (NIEHS), "Health Effects from Exposure to Power - Line Frequency Electric and Magnetic Fields," 1999

[2] World Health Organization (WHO), "Electro-magnetic fields and public health: exposure to extremely low frequency fields," Geneva, Switzerland, 2007.

[3] International Commission on Non-Ionizing Radiation Protection (ICNIRP), "Guidelines for Limiting Exposure to Time-Varying Electric, Magnetic, and Electromagnetic Fields (up to $300 \mathrm{GHz}$ )," Health Physics, vol. 74, pp. 494-522, 1998.

[4] ICNIRP, "Guidelines for Limiting Exposure to Time-Varying Electric and Magnetic Fields (1 Hz-100 kHz)," Health Physics, vol. 96, pp. 818-836, 2010

[5] G. Schmid, R. Überbacher, and P. Göth, "ELF and LF magnetic field exposure in hybrid- and electric cars," presented at the Proceedings of Bioelectromagnetics Conference, Davos, Switzerland, 2009.

[6] P. C. Moreno-Torres, M. Lafoz, J. M. Lopez, and J. R. Arribas, "Measurement of the Electromagnetic Field inside a Battery Electric 
Vehicle," presented at the European Electric Vehicle Congress (EEVC), Brussels, Belgium, 2011.

[7] A. Vassilev, A. Ferber, C. Wehrmann, O. Pinaud, M. Schilling, and A. R. Ruddle, "Magnetic Field Exposure Assessment in Electric Vehicles," Electromagnetic Compatibility, IEEE Transactions on, vol. 57, pp. 3543, 2015.

[8] R. Hareuveny, M. Sudan, M. Halgamuge, Y. Yaffe, Y. Tzabari, D. Namir, et al., "Characterization of Extremely Low Frequency Magnetic Fields from Diesel, Gasoline and Hybrid Cars under Controlled Conditions," International Journal of Environmental Research and Public Health, vol. 12, p. 1651, 2015.

[9] B. Frieske, M. Kloetzke, and F. Mauser, "Trends in vehicle concept and key technology development for hybrid and battery electric vehicles," in Electric Vehicle Symposium and Exhibition (EVS27), 2013 World, 2013, pp. 1-12.

[10] M. C. Di Piazza, A. Ragusa, and G. Vitale, "Effects of Common-Mode Active Filtering in Induction Motor Drives for Electric Vehicles," Vehicular Technology, IEEE Transactions on, vol. 59, pp. 2664-2673, 2010.

[11] D. Hamza, M. Pahlevaninezhad, and P. K. Jain, "Implementation of a Novel Digital Active EMI Technique in a DSP-Based DC/DC Digital Controller Used in Electric Vehicle (EV)," Power Electronics, IEEE Transactions on, vol. 28, pp. 3126-3137, 2013.

[12] A. R. Ruddle and R. Armstrong, "Review of current EMC standards in relation to vehicles with electric powertrains," in Electromagnetic Compatibility (EMC EUROPE), 2013 International Symposium on, 2013, pp. 298-303.

[13] S. Jeschke and H. Hirsch, "Investigations on the EMI of an electric vehicle traction system in dynamic operation," in Electromagnetic Compatibility (EMC Europe), 2014 International Symposium on, 2014, pp. 420-425.

[14] M. Halgamuge, C. D. Abeyrathne, and P. Mendis, "Measurement and analysis of electromagnetic fields from trams, trains, and hybrid cars," Radiation Protection Dosimetry, vol. 141, pp. 255-268, 2010.

[15] P. Concha Moreno-Torres, J. Lourd, M. Lafoz, and J. R. Arribas, "Evaluation of the Magnetic Field Generated by the Inverter of an Electric Vehicle," Magnetics, IEEE Transactions on, vol. 49, pp. 837844, 2013.

[16] A. R. Ruddle and L. Low, "Impact of bodyshell on low frequency magnetic fields due to electric vehicle power cables," in Electromagnetic Compatibility (EMC EUROPE), 2012 International Symposium on, 2012, pp. 1-6.

[17] A. R. Ruddle, L. Low, and A. Vassilev, "Evaluating low frequency magnetic field exposure from traction current transients in electric vehicles," in Electromagnetic Compatibility (EMC EUROPE), 2013 International Symposium on, 2013, pp. 78-83.

[18] ICNIRP, "Guidelines on limits of exposure to static magnetic fields," Health Physics, vol. 96, pp. 504-514, 2009.

[19] WHO, Framework for Developing Health-Based EMF Standards. Geneva, Switzerland, 2006.

[20] D. Linden, Handbook of Batteries, 3d ed.: McGraw-Hill, 2001.

[21] P. Concha Moreno-Torres, P. Velez, M. Lafoz, and J. R. Arribas, "Flexible low-cost system to test batteries and ultracapacitors for electric and hybrid vehicles in real working conditions," in World Electric Vehicle Symposium and Exhibition (EVS27), 2013.

[22] P. J. Grbovic, "Interface DC-DC Converters," in Ultra-Capacitors in Power Conversion Systems: Analysis, Modeling and Design in Theory and Practice, ed: Wiley-IEEE Press, 2013, pp. 216 - 313.

[23] H. Di, J. Noppakunkajorn, and B. Sarlioglu, "Comprehensive Efficiency, Weight, and Volume Comparison of SiC- and Si-Based Bidirectional DC-DC Converters for Hybrid Electric Vehicles," Vehicular Technology, IEEE Transactions on, vol. 63, pp. 3001-3010, 2014.

[24] L. Zhihao, O. Onar, A. Khaligh, and E. Schaltz, "Design and Control of a Multiple Input DC/DC Converter for Battery/Ultra-capacitor Based Electric Vehicle Power System," in Applied Power Electronics Conference and Exposition, 2009. APEC 2009. Twenty-Fourth Annual IEEE, 2009, pp. 591-596.

[25] ICNIRP, "Guidance on determining compliance of exposure to pulsed and complex non-sinusoidal waveforms below $100 \mathrm{kHz}$ with ICNIRP guidelines," Health Physics, vol. 84, pp. 383-387, 2003.

[26] K. Jokela, "Restricting exposure to pulsed and broadband magnetic fields," Health Physics, vol. 79, pp. 373-388, 2000.

[27] J. Larminie and J. Lowry, Electric Vehicle Technology Explained, 2nd ed.: John Wiley \& Sons, Ltd, 2012.
[28] J. Ko, S. Ko, H. Son, B. Yoo, J. Cheon, and H. Kim, "Development of Brake System and Regenerative Braking Cooperative Control Algorithm for Automatic-Transmission-Based Hybrid Electric Vehicles," Vehicular Technology, IEEE Transactions on, vol. 64, pp. 431-440, 2015.

[29] E. Schaltz, "Electrical Vehicle Design and Modeling," in Electric Vehicles - Modelling and Simulations, 1st ed: InTech, 2011.

[30] M. Yilmaz and P. T. Krein, "Review of Battery Charger Topologies, Charging Power Levels, and Infrastructure for Plug-In Electric and Hybrid Vehicles," Power Electronics, IEEE Transactions on, vol. 28, pp. 2151-2169, 2013

[31] K. Rajashekara, "Parallel between More Electric Aircraft and Electric/Hybrid Vehicle Power Conversion Technologies," Electrification Magazine, IEEE, vol. 2, pp. 50-60, 2014.

[32] A. Ostadi and M. Kazerani, "A Comparative Analysis of Optimal Sizing of Battery-only, Ultracapacitor-only, and Battery-Ultracapacitor Hybrid Energy Storage Systems for a City Bus," Vehicular Technology, IEEE Transactions on, vol. PP, pp. 1-1, 2014.

[33] F. Machado, J. P. F. Trovao, and C. H. Antunes, "Effectiveness of Supercapacitors in Pure Electric Vehicle Using a Hybrid Meta-Heuristic Approach," Vehicular Technology, IEEE Transactions on, vol. PP, pp. 1-1, 2015.

[34] L. Giaccone, C. Ragusa, O. Khan, and M. Manca, "Fast Magnetic Field Modeling for Shielding Systems," Magnetics, IEEE Transactions on, vol. 49, pp. 4128-4131, 2013. 